\title{
Seletividade de herbicidas e dinâmica populacional de plantas daninhas na cultura do girassol para a produção de biodiesel ${ }^{1}$
}

\author{
Herbicides selectivity and weeds population dynamics in sunflower crop for \\ biodiesel production
}

Maria Helena Tabim Mascarenhas ${ }^{2}$; Décio Karam ${ }^{3}$; José Francisco Rabelo Lara ${ }^{4}$

Resumo - Os experimentos foram instalados em Prudente de Morais, MG, em 2010 e 2011, com o objetivo de avaliar a seletividade e a eficácia de herbicidas aplicados em pré e pósemergência na cultura do girassol, bem como de estudar a dinâmica populacional de plantas daninhas. O trabalho de 2010 foi conduzido em casa de vegetação em delineamento em blocos ao acaso com 11 tratamentos e três repetições. Os tratamentos foram constituídos por dez herbicidas, sendo quatro pré-emergentes e seis pós-emergentes (alachlor, imazaquin, metribuzin, trifluralin, chlorimuron-ethyl, fenoxaprop-p-ethyl, [fluazifop-p + fomesafen], imazapyr, imazethapyr e sethoxydim) e uma testemunha. Foram avaliados os efeitos fitotóxicos, altura das plantas, número de folhas e a biomassa seca da parte aérea e raízes aos 60 dias após a aplicação. Em 2011 o trabalho foi conduzido a campo, em delineamento de blocos ao acaso com seis tratamentos e quatro repetições. Os tratamentos consistiram dos herbicidas alachlor e trifluralin (préemergência), fenoxaprop-p-ethyl e sethoxydim (pós-emergência) e duas testemunhas (capinada e sem capina). Foram avaliados o ciclo da cultura, o início de florescimento, a altura de plantas, o diâmetro do caule, a maturação fisiológica dos aquênios, o diâmetro de capítulos, o número de plantas quebradas, o número de plantas acamadas, o estande final e o rendimento de aquênios. Com base nos resultados pode-se concluir que os herbicidas que apresentaram maior fitotoxicidade ao girassol foram: imazaquin, metribuzin, chlorimuron-ethyl, [fluazifop-p + fomesafen], imazapyr e imazethapyr. Os herbicidas pré-emergentes alachlor e trifluralin, e os pós-emergentes fenoxaprop-p-ethyl e sethoxydim mostraram-se seletivos para o girassol. $\mathrm{O}$ fenoxaprop-p-ethyl poderá vir a ser utilizado em um programa de manejo integrado de plantas daninhas no girassol, pois apenas trifluralin, alachlor e sethoxydim são herbicidas registrados para esta cultura.

Palavras-chaves: Helianthus annuиs L., fitotoxicidade, produtividade, oleaginosas

Abstract - Experiments were conducted in Prudente de Morais County, Minas Gerais State, in 2010 and 2011 years, with the objective of to evaluate selectivity and efficiency of pre and postemergence herbicides in sunflower crop, as well as to study weeds populacional dynamic. The work conducted in 2010 was carried out in greenhouse, in a randomized complete block design, with 11 treatments and three replications. Treatments consisted by ten herbicides, four in pre emergence and six in post-emergent of the crop (alachlor, imazaquin, metribuzin, trifluralin, chlorimuron-ethyl, fenoxaprop-p-ethyl, [fluazifop-p + fomesafen], imazapyr, imazethapyr e sethoxydim) and a check. The following characteristics were evaluated: phytotoxicity effects,

\footnotetext{
${ }^{1}$ Recebido para publicação em 09/02/2012 e aceito em 25/08/2012.

${ }^{2}$ MSc. Pesquisadora da EPAMIG, Av. José Cândido da Silveira, 1647 - União - CEP : 31170-495, Belo Horizonte MG - mhtabimm@epamig.br;

${ }^{3}$ Dr. Pesquisador da EMBRAPA/CNPMS;

${ }^{4}$ Eng. Agro. Pesquisador da EPAMIG.
} 
plants height, leaves number and dry biomass of shoot and root 60 days after product applications. In 2011, the work was accomplished in field conditions following a randomized complete block design with six treatments and four replications. The treatments consisted of two pre-emergent herbicides: alachlor and trifluralin, two post-emergence: fenoxaprop-p-ethyl and sethoxydim and two checks (with and without weeding). Crop cycle, flowering initial, plant height, stem diameter, achenes physiologically mature, chapters diameter, broken plants number, lodged plants number, final stand and achenes yield were evaluated. Based on the obtained results, it was possible to conclude that herbicides that showed higher toxicity to sunflower plants were: imazaquin, metribuzin, chlorimuron-ethyl, [fomesafen + fluazifop-p], imazapyr and imazethapyr. The pre emergent herbicides alachlor, trifluralin, fenoxaprop-p-ethyl and sethoxydim were selective to sunflower crop. Fenoxaprop-p-ethyl herbicide may be used in a program of weeds integrated management in sunflower crop, because only trifluralin, alachlor and sethoxydim herbicides are registered for this crop in Brazil.

Keywords: Helianthus annuus L., phytotoxicity, yield, oil crop

\section{Introdução}

O girassol é uma planta da família Asteraceae, produtora de grãos, e de fácil adaptabilidade. Produz óleo com propriedades organolépticas de excelente qualidade industrial e nutricional, e, num futuro próximo, poderá produzir biodiesel (Paes, 2005; Erasmo et al., 2010). Por apresentar resistência à seca e à baixa temperatura está adaptado a diferentes regiões agrícolas do País, podendo ter sua área cultivada expandida (Brighenti et al., 2004; Castro \& Farias, 2005).

Apresenta desenvolvimento inicial lento até os 40 dias após a emergência, sendo, portanto, suscetível à presença de outras plantas que venham a germinar na área. Dentre os principais fatores que diminuem a produtividade da cultura destaca-se a interferência causada pelas plantas daninhas. A presença dessas espécies durante o início do ciclo da cultura resulta em plantas cloróticas, de menor porte, com diminuição severa da área foliar, diâmetro de caule e capítulo (Leite et al., 2007). Brighenti et al. (2004) constataram que a presença das plantas daninhas com a cultura do girassol ocasionou perdas diárias de $1,1 \mathrm{~kg}$ $\mathrm{ha}^{-1}$ no rendimento de óleo e de $2,5 \mathrm{~kg} \mathrm{ha}^{-1}$ na produtividade. $\mathrm{Na}$ ausência de plantas daninhas, até 30 dias após a emergência, o ganho diário foi de $6,5 \mathrm{~kg} \mathrm{ha}^{-1}$ no rendimento de óleo e de $14,4 \mathrm{~kg} \mathrm{ha}^{-1}$ na produtividade.
Para o controle de plantas daninhas na cultura do girassol apenas os herbicidas trifluralin e alachlor estão registrados (MAPA, 2011). Glyphosate, paraquat, sulfosate, glufosinate, diuron e 2,4-D são recomendados para o manejo de dessecação de plantas daninhas em sistema de plantio direto (Castro et al., 1997). No entanto, herbicidas como oxyfluorfen, linuron, aclonifen, oxadiargil, diflufenican, metolachlor, sulfentrazone, prometrine, alachlor e acetochlor+oxyflorfen foram seletivos para o girassol, cultivar Morgan M 742, apresentando potencial de utilização na cultura (Brighenti et al., 2002b).

O girassol é sensível a diferentes grupos de herbicidas, destacando-se as triazinas e as imidazolinonas. Esses produtos são muito utilizados nas culturas do milho e da soja que antecedem o girassol (Castro et al., 1997), e tem longo efeito residual no solo, chegando até 180 dias. Rossi (1998) informa que em culturas de soja onde foi aplicado o imazaquin podem aparecer injúrias ao girassol semeado em sucessão. Fleck \& Vidal (1994) observaram danos severos à cultura do girassol quando semeado no mesmo dia da aplicação do imazaquin. Por esse motivo não se deve semear o girassol em áreas onde tenham sido utilizados esses produtos. Brighenti et al. (2002a) concluíram que a sensibilidade da cultura é maior em ordem decrescente de fitotoxicidade 
ao diclosulan $>$ imazaquin $>$ imazethapyr. Entretanto, quando foi aplicada à dose recomendada do imazaquin na cultura da soja, resíduos desse herbicida não influenciaram no desenvolvimento e na produtividade do girassol semeado 90 dias após a aplicação do produto (Brighenti et al., 2002a; Brighenti et al., 2008).

Uma estratégia eficiente de controle de plantas daninhas na cultura do girassol deve incluir medidas de manejo integrado e entre elas herbicidas seletivos à cultura. Trabalhos com esse objetivo, foram realizados por Brighenti et al. (2000a, b, c, 2002a, b), Castro et al. (2002), Concenço et al. (2007) e Erasmo et al., (2010). No entanto, ainda são limitadas as informações referentes à seletividade de herbicidas na cultura do girassol, sendo necessário mais estudos com essa abordagem.

$\mathrm{O}$ presente trabalho teve como objetivo avaliar a seletividade e eficácia de herbicidas aplicados em pré e pós-emergência na cultura do girassol, bem como de estudar a dinâmica populacional de plantas daninhas nessa cultura.

\section{Material e Métodos}

\section{Experimento em telado - Seletividade de herbicidas}

$\mathrm{O}$ experimento foi instalado em 04/02/2010, em vasos com capacidade de 10 $\mathrm{dm}^{3}$ de solo, em um telado na Fazenda Experimental de Santa Rita, da EPAMIG/CTCO. O delineamento experimental utilizado foi o de blocos ao acaso com 11 tratamentos e três repetições. Os tratamentos foram constituídos por dez herbicidas, sendo quatro pré-emergentes e seis pós-emergentes e uma testemunha que recebeu apenas água no dia da aplicação dos produtos (Tabela 1). As parcelas foram compostas por 12 vasos com uma planta. As sementes de girassol, cultivar Embrapa 122-V2000, recomendada para o Estado em Minas Gerais (Leite et al., 2007), foram semeadas com cinco sementes por vaso, e 20 dias após a emergência realizou-se o desbaste deixando-se uma plantas por vaso.

A amostra do solo utilizado para preenchimento dos vasos apresentou as seguintes características químicas e físicas: $\mathrm{pH}$ em água de 5,8; 4,23 cmol $_{\mathrm{c}} \mathrm{dm}^{-3} \mathrm{de} \mathrm{H}+\mathrm{Al}$ $\left[\mathrm{Ca}(\mathrm{OAc})_{2} 0,5 \mathrm{~mol} \mathrm{~L}^{-1} \mathrm{pH} 7,0\right] ; 0,10 \mathrm{cmol}_{\mathrm{c}} \mathrm{dm}^{-}$ ${ }^{3} \mathrm{de}^{3+3} ; 4,74 \mathrm{cmol}_{\mathrm{c}} \mathrm{dm}^{-3}$ de Ca ${ }^{2+}$ e $0,77 \mathrm{cmol}_{\mathrm{c}}$ $\mathrm{dm}^{-3}$ de $\mathrm{Mg}^{2+}\left(\mathrm{KCl} 1 \mathrm{~mol} \mathrm{~L}^{-1}\right) ; 46 \mathrm{mg} \mathrm{dm}{ }^{-3}$ de $\mathrm{K} \mathrm{e} 6,4 \mathrm{mg} \mathrm{dm}^{-3}$ de $\mathrm{P}$ (Mehlich-1); 13,20\% de areia grossa; $11,56 \%$ de areia fina; $26,4 \%$ de silte e $49,20 \%$ de argila, sendo as análises feitas no Laboratório de Química Agrícola do Instituto Mineiro de Agropecuária (IMA), Belo Horizonte, MG.

$\mathrm{Na}$ adubação de semeadura utilizou-se $100 \mathrm{~kg} \mathrm{ha}^{-1}$ de sulfato de amônio, $610 \mathrm{~kg} \mathrm{ha}^{-1} \mathrm{de}$ superfosfato triplo, $120 \mathrm{~kg} \mathrm{ha}^{-1} \mathrm{de}$ cloreto de potássio e $50 \mathrm{~kg} \mathrm{ha}^{-1}$ de FTE. Na adubação de cobertura, 45 dias após a emergência das plantas, utilizou-se $200 \mathrm{~kg} \mathrm{ha}^{-1}$ de sulfato de amônio, conforme recomendações da Comissão de Fertilidade do Solo do Estado de Minas Gerais (1999).

A aplicação dos herbicidas em préemergência da cultura foi realizada um dia após a semeadura das sementes, em 05/02/2010, no período de 7:50h às $8: 45 \mathrm{~h}$, com temperaturas mínima e máxima de $22^{\circ} \mathrm{C}$ e $25^{\circ} \mathrm{C}$, respectivamente. A pulverização foi realizada com um pulverizador pressurizado a $\mathrm{CO}_{2}$, equipado com ponta leque Magno 110.03, pressão de $2,75 \mathrm{kgf} \mathrm{cm}^{-2}$ e consumo de calda de $210 \mathrm{~L} \mathrm{ha}^{-1}$. A aplicação dos produtos em pós-emergentes foi desenvolvida em $23 / 02 / 2010$, no período de $8: 50 \mathrm{~h}$ às $10: 10 \mathrm{~h}$, com temperaturas mínima e máxima de $30^{\circ} \mathrm{C}$ e $33^{\circ} \mathrm{C}$, respectivamente.

Após a semeadura foi realizada irrigação de $500 \mathrm{~mL}$ de água via gotejamento em todos os vasos. O objetivo foi fornecer uma quantidade de água suficiente para repor as perdas por evapotranspiração. $\mathrm{O}$ gotejador aspergia $14 \mathrm{~mL} \mathrm{~m}^{-1}$.

A seletividade dos herbicidas à cultura do girassol foi avaliada pelas seguintes 
características: fitointoxicação (\%) do girasso, através de avaliações visuais dos sintomas de fitotoxicidade aos 10, 20, e 30 após a emergência (pré-emergência) ou da aplicação dos herbicidas (pós-emergência), utilizando escala de notas, onde $0 \%$ significa nenhum efeito de dano às plantas e $100 \%$, morte total, conforme metodologia da SBCPD (1995); altura das plantas, aos 10, 20 e 30 dias após a emergência (pré-emergência) ou da aplicação (pós-emergência); número de folhas aos 10, 20 e 30 dias após a emergência (pré-emergência) ou da aplicação (pós-emergência); biomassa seca da parte aérea e raízes (secagem a $65^{\circ} \mathrm{C}$, em estufa com ventilação forçada por 72 horas), das plantas colhidas aos 60 dias após a emergência (pré-emergência) ou da aplicação (pós-emergência).

Para a interpretação dos resultados, os dados foram submetidos à análise de variância e suas médias ao teste Tukey a $5 \%$ de probabilidade, utilizando-se o Programa SAEG (Ribeiro Jr., 2001).

\section{Experimento em campo - Dinâmica populacional de plantas daninhas}

Para o estudo da dinâmica populacional de plantas daninhas o experimento foi instalado em 09/05/2011, na Fazenda Experimental de Santa Rita, pertencente a EPAMIG Centro Oeste, com a cultivar Embrapa 122-V2000 (Leite et al., 2007a). A fazenda está localizada no município de Prudente de Morais/MG, a $19^{\circ} 28^{\prime} 00^{\prime}$ ' de latitude sul e $44^{\circ} 15^{\prime} 99^{\prime}$ ' de longitude oeste. $\mathrm{O}$ clima da região está situado entre o Mesotérmico Subtropical Úmido $(\mathrm{Cw})$ e Tropical Úmido (Aw) com verão quente e chuvoso e estação seca de maio a outubro. A amostra do solo, classificado como Latossolo Vermelho Amarelo, textura argilosa, coletada na camada de $0-20 \mathrm{~cm}$, apresentou as seguintes características químicas e físicas: $6,5 \mathrm{dag} / \mathrm{kg}$ de pH em água; $10,1 \mathrm{mg} / \mathrm{dm}^{3}$ de $\mathrm{P}$ (Mehlich-1); $152 \mathrm{mg} / \mathrm{dm}^{3}$ de K (Mehlich-1); 0,2 mg/dm ${ }^{3}$ de $\mathrm{Na}$ (Mehlich-1); 5,8 cmolc/dm ${ }^{3}$ de Ca (KCL 1 $\mathrm{mol} / \mathrm{L}) ; 1,7 \mathrm{cmolc} / \mathrm{dm}^{3}$ de $\mathrm{Mg}$ (KCL $\left.1 \mathrm{~mol} / \mathrm{L}\right)$;
2,3 cmolc/dm ${ }^{3}$ de $\mathrm{H}+\mathrm{Al}$ (pH SMP); SB (soma de bases) 8\%; t (CTC efetiva) 8\%; T (CTC a pH 7) 10,3\%; V (saturação por bases) $78 \%$; $22 \%$ de areia; $26 \%$ de silte e $52 \%$ de argila. As análises foram realizadas no Laboratório de Solos da Unidade Regional EPAMIG Norte de Minas, Nova Porteirinha/MG.

$\mathrm{Na}$ adubação de semeadura utilizou-se $20 \mathrm{~kg}$ de $\mathrm{N} \mathrm{ha}^{-1}$ (ureia), $50 \mathrm{~kg} \mathrm{ha}^{-1}$ de $\mathrm{P}_{2} \mathrm{O}_{5}$ (superfosfato simples), $50 \mathrm{~kg}^{-1} \mathrm{ha}^{-1} \quad \mathrm{~K}_{2} \mathrm{O}$ (cloreto de potássio) e $50 \mathrm{~kg} \mathrm{ha}^{-1}$ de FTE. Na adubação de cobertura, 50 dias após a semeadura, utilizou-se equivalente a $40 \mathrm{~kg}$ de $\mathrm{N}^{-1}{ }^{-1}$ (ureia), conforme as recomendações da Comissão de Fertilidade do Solo do Estado de Minas Gerais (1999).

O delineamento experimental adotado foi $\mathrm{o}$ de blocos casualizados com seis tratamentos e quatro repetições. Os herbicidas alachlor, trifluralin, fenoxaprop-p-ethyl e sethoxydim mostraram-se seletivos à cultura dogirassol em trabalho de Mascarenhas et al. (2010) e foram utilizados neste estudo, em que se contemplou como a avaliação da produção de aquênios. Os tratamentos consistiram na aplicação: alachlor (3.120 $\left.\mathrm{g} \mathrm{ha}^{-1}\right)$ e trifluralin (2.280 $\mathrm{g} \mathrm{ha}^{-1}$ ) em pré-emergência; fenoxapropp-ethyl (132 $\left.\mathrm{g} \mathrm{ha}^{-1}\right)$ e sethoxydim $\left(258 \mathrm{~g} \mathrm{ha}^{-1}\right)$ em pós-emergência e duas testemunhas, sendo, uma capinada e uma sem capina, que receberam apenas água no dia da aplicação dos herbicidas. A semeadura foi realizada manualmente, no espaçamento de $0,70 \mathrm{~m}$ entre fileiras e $0,25 \mathrm{~m}$ entre plantas. As parcelas foram compostas por 48 plantas, com área total de $9 \mathrm{~m}^{2}$ e área total do experimento de $216 \mathrm{~m}^{2}$.

A aplicação dos herbicidas em préemergência foi realizada um dia após a semeadura da cultura, em 10/05/2011, entre 8:00 e 8:30 h, com temperaturas mínima e máxima de $23^{\circ} \mathrm{C}$ e $26^{\circ} \mathrm{C}$, respectivamente. A pulverização foi realizada com um pulverizador pressurizado a $\mathrm{CO}_{2}$, equipado com pontas tipo leque Magno 110.03, pressão de $2,75 \mathrm{kgf} \mathrm{cm}^{-2}$ e consumo de calda de $210 \mathrm{~L}$ $\mathrm{ha}^{-1}$. A aplicação em pós-emergência foi 
realizada em 06/06/2011, no período de 9:30 h às 10:00 h com temperaturas mínima e máxima de $19^{\circ} \mathrm{C}$ e $28^{\circ} \mathrm{C}$, respectivamente.

O levantamento das plantas daninhas foi realizado em três épocas distintas: aos 20, 40 e 60 dias após a aplicação dos produtos. Foi utilizado o método do quadrado inventário, aplicado por meio de quadrado de $1,0 \mathrm{~m}$ de lado lançado duas vezes, em cada parcela, com uma área amostrada por tratamento de $8 \mathrm{~m}^{2}$. A cada arremesso foram identificados as espécies daninhas e o número de indivíduos por quadrado. Posteriormente, foi realizada a pesagem da massa fresca das plantas amostradas e após a secagem em estufa de circulação forçada a $65{ }^{0} \mathrm{C}$ por 72 horas.

Para análise da estrutura das comunidades de plantas invasoras foram calculados os seguintes parâmetros: frequência das espécies - informa sobre a distribuição das espécies pelas áreas; densidade - representa a quantidade de plantas por unidade de área em cada espécie; abundância - representa as espécies que ocorrem concentradas em determinados pontos; frequência relativa, densidade relativa e abundância relativa informações de cada espécie, em relação a todas as outras encontradas na área; e índice de valor de importância - indica espécies mais importantes dentro da área estudada. No cálculo desses parâmetros foram utilizadas as fórmulas de Mueller-Dombois \& Ellenberg (1974), apresentadas por:

Índice de Valor de Importância (IVI) = FreqR + DenR + AbuR

Onde,

Frequência $($ Freq $)=\mathrm{N}^{\mathrm{o}}$ de parcelas que contem a espécie / $\mathrm{N}^{\mathrm{O}}$ total de parcelas utilizadas;

Densidade $($ Den $)=\mathrm{N}^{\mathrm{O}}$ total $\mathrm{de}$ indivíduos por espécie / Área total coletada;

Abundância $(\mathrm{Abu})=\mathrm{N}^{\mathrm{o}}$ total de indivíduos por espécie / $\mathrm{N}^{\mathrm{o}}$ total de parcelas com a espécie;
Frequência Relativa (FreqR) = Frequência da espécie * 100 / Freqüência total das espécies;

Densidade Relativa (DenR) = Densidade da espécie * 100 / Densidade total das espécies;

Abundância Relativa (AbuR) = Abundância da espécie * 100 / Abundância total das espécies.

Para fins de avaliação dos resultados do ensaio, foram consideradas as seguintes características: ciclo e/ou número de dias da semeadura à colheita, considerando a média de todas as plantas da parcela; início de florescimento, considerando o período em dias decorrido entre a semeadura e as primeiras flores liguladas, que freqüentemente são amarelas; altura de plantas (m), medida na floração plena, do nível do solo até a inserção do capítulo; diâmetro do caule $(\mathrm{cm})$, medido a $5 \mathrm{~cm}$ acima do nível do solo, em floração plena; maturação fisiológica dos aquênios em dias, do período decorrido entre a semeadura até $90 \%$ das plantas em capítulos com brácteas de coloração entre amarelo e castanho; diâmetro de capítulos $(\mathrm{cm})$, medido no ponto de maturação fisiológica, número de plantas quebradas, obtido pela contagem de plantas quebradas por ocasião da colheita; número de plantas acamadas, obtido pela contagem das plantas que apresentaram ângulo de inclinação $>45^{\circ}$ por ocasião da colheita; estande final, número de plantas na área útil da parcela, contadas por ocasião da colheita; rendimento de aquênios, em g parcela ${ }^{-1}$, obtidos na área útil.

A colheita ocorreu em 12/09/2011, aos 126 dias após a semeadura, sendo colhidas manualmente todas as plantas da área útil da parcela.

Para a interpretação dos resultados, os dados foram submetidos à análise de variância pelo teste $\mathrm{F}$, e as médias dos tratamentos, comparadas pelo teste de Tukey a 5\% de probabilidade, utilizando-se o Programa SAEG (Ribeiro Jr., 2001). 


\section{Resultados e Discussão}

1). Resultados semelhantes em relação ao imazaquin foram obtidos por Fleck \&Vidal (1994).

Experimento em telado - Seletividade de herbicidas 'Os herbicidas alachlor, trifluralin, Observou-se que os herbicidas metribuzin, chlorimuron-ethyl, [fluazifop-pbutyl + fomesafen], imazapyr e imazethapyr causaram redução significativa na altura das plantas e número de folhas aos $10 \mathrm{DAA}$, sendo que aos 20 DAA já havia ocorrido à morte das plantas. O herbicida imazaquin causou redução fenoxaprop-p-ethyl e sethoxydim não afetaram a altura das plantas e o número de folhas (Tabela 1). Os resultados com o alachlor e o trifluralin eram esperados, pois esses são os únicos produtos registrados para esta cultura (MAPA, 2011). na altura de plantas e número de folhas (Tabela

Tabela 1. Altura de plantas e número de folhas de girassol em relação à testemunha (\%), aos 10, 20 e 30 DAE/DAA ${ }^{(1)}$. Média de três repetições ${ }^{(2)}$. EPAMIG Centro Oeste, 2010.

\begin{tabular}{|c|c|c|c|c|c|c|}
\hline \multirow{4}{*}{ Tratamentos (g i.a. ha $\left.{ }^{-1}\right)$} & \multicolumn{6}{|c|}{ \% em relação à testemunha } \\
\hline & \multicolumn{3}{|c|}{ Altura de plantas } & \multicolumn{3}{|c|}{ Número de folhas } \\
\hline & \multicolumn{3}{|c|}{ DAA } & \multicolumn{3}{|c|}{ DAA } \\
\hline & 10 & 20 & 30 & 10 & 20 & 30 \\
\hline Alachlor (3120) & $88,30 \mathrm{ab}$ & $107,32 \mathrm{a}$ & $105,57 \mathrm{ab}$ & $107,00 \mathrm{a}$ & $125,57 \mathrm{a}$ & $89,80 \mathrm{a}$ \\
\hline Imazaquin $(187,5)$ & $56,46 \mathrm{bc}$ & $56,46 \mathrm{bc}$ & $23,29 \mathrm{c}$ & $54,79 \mathrm{c}$ & $63,26 \mathrm{~b}$ & $35,71 \mathrm{~b}$ \\
\hline Metribuzin (1080) & $14,66 \mathrm{~d}$ & $0,00 \mathrm{~d}$ & $0,00 \mathrm{~d}$ & $18,23 \mathrm{~cd}$ & $0,00 \mathrm{c}$ & $0,00 \mathrm{c}$ \\
\hline Trifluralin (2250) & $104,61 \mathrm{a}$ & $134,70 \mathrm{a}$ & $120,95 \mathrm{a}$ & $105,50 \mathrm{ab}$ & $129,95 \mathrm{a}$ & $97,88 \mathrm{a}$ \\
\hline Chlorimuron-ethyl $(18,75)$ & $48,63 \mathrm{c}$ & $0,00 \mathrm{~d}$ & $0,00 \mathrm{~d}$ & $41,47 \mathrm{c}$ & $0,00 \mathrm{c}$ & $0,00 \mathrm{c}$ \\
\hline Fenoxaprop-p-ethyl (131) & $94,75 \mathrm{a}$ & $95,10 \mathrm{ab}$ & $92,83 \mathrm{~b}$ & $106,60 \mathrm{ab}$ & $97,88 \mathrm{ab}$ & $105,14 \mathrm{a}$ \\
\hline [Fluazifop-p+Fomesafen] $(220+275)$ & $4,59 \mathrm{~d}$ & $0,00 \mathrm{~d}$ & $0,00 \mathrm{~d}$ & $14,04 \mathrm{~d}$ & $0,00 \mathrm{c}$ & $0,00 \mathrm{c}$ \\
\hline Imazapyr (625) & $49,75 \mathrm{c}$ & $35,49 \mathrm{~cd}$ & $0,00 \mathrm{~d}$ & $42,20 \mathrm{~cd}$ & $13,79 \mathrm{c}$ & $0,00 \mathrm{c}$ \\
\hline Imazethapyr (175) & $50,11 \mathrm{c}$ & $0,00 \mathrm{~d}$ & $0,00 \mathrm{~d}$ & $36,98 \mathrm{~cd}$ & $0,00 \mathrm{c}$ & $0,00 \mathrm{c}$ \\
\hline Sethoxydim (253) & $100,35 \mathrm{a}$ & $102,38 \mathrm{ab}$ & $95,83 \mathrm{~b}$ & $99,98 \mathrm{ab}$ & $90,99 \mathrm{ab}$ & $95,81 \mathrm{a}$ \\
\hline Testemunha & $100,00 \mathrm{a}$ & $100,00 \mathrm{ab}$ & $100,00 \mathrm{ab}$ & $100,00 \mathrm{ab}$ & $100,00 \mathrm{ab}$ & $100,00 \mathrm{a}$ \\
\hline F tratamentos & $23,50^{*}$ & $24,39^{*}$ & $132,45^{*}$ & $10,29 *$ & $29,32 *$ & $70,58^{*}$ \\
\hline $\mathrm{CV}(\%)$ & 19,47 & 31,97 & 16,19 & 30,88 & 30,80 & 21,59 \\
\hline
\end{tabular}

${ }^{(1)}$ DAE/DAA: dias após a emergência (pré-emergência) (DAE) ou dias após a aplicação (pós-emergência) (DAA). ${ }^{(2)}$ Médias na mesma coluna seguidas pela mesma letra não diferem entre si em nível de $(\mathrm{p} \leq 0,05)$ pelo teste de Tukey.*( $\leq 0,05)$.

Os herbicidas metribuzin, chlorimuronethyl, [fluazifop-p-butyl + fomesafen], imazapyr e imazethapyr foram fitotóxicos para a cultura, provocando a morte das plantas. $\mathrm{O}$ herbicida imazaquin causou alta fitotoxicidade com redução drástica de biomassa seca (Tabela 2).

O girassol é sensível a diferentes grupos de herbicidas, destacando-se as triazinas e as imidazolinonas. Esses produtos são muito utilizados nas culturas do milho e da soja que antecedem o girassol (Castro et al., 1997), e tem longo efeito residual no solo, chegando até 180 dias. Rossi (1998) informou que em culturas de soja onde foi aplicado o imazaquin podem aparecer injúrias ao girassol semeado em sucessão. Brighenti et al. (2002a) concluíram que a sensibilidade da cultura é maior em ordem decrescente de fitotoxicidade ao diclosulan > imazaquin > imazethapyr. Entretanto, quando foi aplicada a dose recomendada do imazaquin na cultura da soja, resíduos desse herbicida não influenciaram no desenvolvimento e produtividade das plantas de girassol semeado 90 dias após a aplicação do produto (Brighenti et al., 2002b; Brighenti et al., 2008). 
Tabela 2. Percentuais de sintomas de fitointoxicação atribuídos às plantas do girassol aos 10, 20 e $30 \mathrm{DAA}^{(1)}$, pelos diferentes herbicidas e biomassa seca do girassol em \% em relação à testemunha nos diferentes tratamentos. Média de três repetições ${ }^{(2)}$. EPAMIG Centro Oeste, 2010.

\begin{tabular}{|c|c|c|c|c|}
\hline \multirow{3}{*}{$\begin{array}{c}\text { Tratamentos } \\
(\text { g i.a. ha } \\
\text { (-1) }\end{array}$} & \multirow{2}{*}{\multicolumn{3}{|c|}{$\frac{\text { Fitotoxicidade }(\%)}{\text { DAA }}$}} & \multirow{3}{*}{$\begin{array}{c}\begin{array}{c}\text { Massa seca } \\
\text { (\% da testemunha) }\end{array} \\
\text { 30 DAA }\end{array}$} \\
\hline & & & & \\
\hline & 10 & 20 & 30 & \\
\hline Alachlor (3120) & 0 & 0 & $\overline{0}$ & $84,29 \mathrm{ab}$ \\
\hline Imazaquin $(187,5)$ & 70 & 70 & 70 & $7,99 \mathrm{c}$ \\
\hline Metribuzin (1080) & 100 & 100 & 100 & $0,00 \mathrm{c}$ \\
\hline Trifluralin (2250) & 0 & 0 & 0 & $122,55 \mathrm{a}$ \\
\hline Chlorimuron-ethyl $(18,75)$ & 70 & 100 & 100 & $6,96 \mathrm{c}$ \\
\hline Fenoxaprop-p-ethyl (131) & 0 & 0 & 0 & $107,97 \mathrm{ab}$ \\
\hline [Fluazifop-p+Fomesafen] $(220+275)$ & 83 & 100 & 100 & $5,78 \mathrm{c}$ \\
\hline Imazapyr (625) & 70 & 88 & 100 & $5,67 \mathrm{c}$ \\
\hline Imazethapyr (175) & 70 & 95 & 100 & $5,22 \mathrm{c}$ \\
\hline Sethoxydim (253) & 0 & 0 & 0 & $115,01 \mathrm{a}$ \\
\hline Testemunha & 0 & 0 & 0 & $100,00 \mathrm{ab}$ \\
\hline F tratamentos & - & - & - & $5,89^{*}$ \\
\hline $\mathrm{CV}(\%)$ & - & - & - & 74,73 \\
\hline
\end{tabular}

Médias na mesma coluna seguidas pela mesma letra não diferem entre si pelo teste de Tukey.*(p $\leq 0,05)$. NS = não significativo.

\section{Experimento em campo - Dinâmica populacional de plantas daninhas}

No levantamento realizado na área experimental foram identificadas 11 espécies pertencentes a sete famílias botânicas. A família Asteraceae apresentou o maior número de espécies (quatro), seguida da Amaranthaceae, com duas espécies. As demais famílias estavam presentes com apenas uma espécie cada (Tabela 3). Em levantamento fitossociológico de plantas espontâneas no cultivo do girassol, Brighenti et al. (2003) e Silva et al. (2010) observaram que as espécies pertencentes às famílias Poaceae, Asteraceae e Euphorbiaceae foram as que ocorreram em maior número.

Tabela 3. Espécies de plantas espontâneas encontradas na área experimental de cultivo do girassol. EPAMIG Centro Oeste, 2010.

\begin{tabular}{lccc}
\hline \multicolumn{1}{c}{ Nome científico } & Nome vulgar & Família & Código \\
\hline Acanthospermum hispidum DC. & carrapicho-de-carneiro & Asteraceae & ACNHI \\
Alternanthera tenella Colla & carrapichinho & Amaranthaceae & ALRTE \\
Amaranthus lividus L. & caruru & Amaranthaceae & AMALI \\
Brachiaria decumbens Stapf & capim-braquiária & Poaceae & BRADC \\
Commelina benghalensis L. & trapoeraba & Commelinaceae & COMBE \\
Cyperus rotundus L. & tiririca & Cyperaceae & CYPRO \\
Emilia sonchifolia L. & serralha & Asteraceae & EMISO \\
Galinsoga parviflora Cav. & botão-se-ouro & Asteraceae & GASPA \\
Nicandra physaloides (L.) Pers. & joá-de-capote & Solanaceae & NICPH \\
Parthenium hysteroforus L. & losna-branca & Asteraceae & PTNHY \\
Raphanus sativus L. & nabo-comum & Brassicaceae & RAPSV \\
\hline
\end{tabular}

As espécies com maior densidade populacional foram: Cyperus rotundus $(63$ plantas $\left.\mathrm{m}^{-2}\right)$, Brachiaria decumbens $(6,5$ plantas $\left.\mathrm{m}^{-2}\right)$ e Raphanus sativus $\left(6,5\right.$ plantas $\mathrm{m}^{-}$ ${ }^{2}$ ) de um total de 85 plantas $\mathrm{m}^{-2}$ presentes na área experimental (Anexos 1, 2 e 3). Segundo Brighenti et al. (2003), Cyperus sp. destacou-se como entre as espécie de maior ocorrência em áreas cultivadas com a cultura do girassol. 
A infestação de plantas daninhas representa um problema de difícil solução para a agricultura dado ao elevado número de espécies invasoras, que emergem em épocas diferentes e competem de forma diferenciada com as culturas agrícolas, interferindo sobremaneira na produtividade das plantas cultivadas e na operacionalização dos sistemas de produção (Karam \& Cruz, 2004; Pitelli \& Pitelli, 2005).

Da análise da dinâmica populacional de C. rotundus (Anexo 1), em função da aplicação dos herbicidas, observou-se que não houve alteração no padrão da densidade relativa em função da aplicação dos produtos. De acordo com Balduíno et al. (2005), a densidade relativa é o parâmetro que mais contribui para a importância de uma espécie em uma determinada área.

Quando da análise do índice de importância, ou seja, da importância de $C$. rotundus dentro da população estudada, a aplicação dos herbicidas avaliados, não alterou o padrão observado na testemunha sem qualquer aplicação de herbicida (Anexo 1). Em experimento com soja a alta infestação de $C$. rotundus foi responsável pela redução de $78 \%$ no número de vagens por planta, um dos principais componentes da produção (Silva et al., 2008).

Análise do levantamento realizado indicou que os herbicidas alachlor e trifluralin promoveram mudanças nos padrões de frequência de $R$. sativus aos 60 DAA, ocasionando a mortalidade das plantas (Anexo 2). Quando da análise do índice de importância, notou-se que a aplicação dos herbicidas pós-emergentes fenoxaprop-p-ethyl e sethoxydim não alteraram o padrão observado em relação à testemunha sem qualquer aplicação de herbicida. Resultados obtidos por Bianchi et al. (2011), em soja, mostraram que a competição com nabo forrageiro na fase vegetativa da cultura reduziu a estatura da planta, o comprimento médio dos ramos e a produtividade de grãos.

Em relação à dinâmica populacional de $B$. decumbens quando da análise do índice de importância, notou-se que a aplicação de sethoxydim aos 60 DAA, alterou o padrão observado em relação à testemunha sem qualquer aplicação de herbicida (Anexo 3).

$\mathrm{Na}$ Tabela 4 estão apresentados os resultados das avaliações do número, massa verde e massa seca das plantas daninhas em valores relativos à testemunha sem capina. Não houve diferença significativa entre os tratamentos em todos os períodos avaliados, entretanto, observou-se aos 60 DAA uma redução na massa seca dessas espécies de $58,5 \%, 44,3 \%$ e $41,9 \%$, quando da utilização do fenoxaprop-p-ethyl, sethoxidym e trifluralin, respectivamente (Tabela 4).

Tabela 4. Valores relativos (\%) do número, massa verde e massa seca de plantas daninhas, em relação à testemunha sem capina aos 20, 40 e 60 dias após a aplicação dos herbicidas (DAA), na cultura do girassol. Média de 4 repetições. EPAMIG Centro Oeste, 2011.

\begin{tabular}{|c|c|c|c|c|c|c|c|c|c|}
\hline \multirow{3}{*}{ Tratamentos } & \multicolumn{9}{|c|}{ \% em relação à testemunha } \\
\hline & \multicolumn{3}{|c|}{$\mathrm{N}^{\mathbf{O}}$ de plantas daninhas } & \multicolumn{3}{|c|}{ Massa verde } & \multicolumn{3}{|c|}{ Massa seca } \\
\hline & $\begin{array}{c}\mathbf{2 0} \\
\text { DAA }\end{array}$ & $\begin{array}{c}\text { 40 } \\
\text { DAA }\end{array}$ & $\begin{array}{c}60 \\
\text { DAA }\end{array}$ & $\begin{array}{c}20 \\
\text { DAA }\end{array}$ & $\begin{array}{c}\mathbf{4 0} \\
\text { DAA }\end{array}$ & $\begin{array}{c}\text { 60 } \\
\text { DAA }\end{array}$ & $\begin{array}{c}\mathbf{2 0} \\
\text { DAA }\end{array}$ & $\begin{array}{c}\mathbf{4 0} \\
\text { DAA }\end{array}$ & $\begin{array}{c}\text { 60 } \\
\text { DAA }\end{array}$ \\
\hline Alachlor & 105,64 & 141,96 & 87,91 & 118,97 & 91,56 & 73,01 & 95,04 & 101,51 & 70,198 \\
\hline Trifluralin & 91,64 & 98,53 & 70,10 & 104,13 & 170,24 & 47,36 & 90,99 & 152,43 & 58,01 \\
\hline Fenoxapro-p-ethyl & 151,96 & 103,02 & 75,25 & 78,52 & 121,89 & 131,47 & 124,79 & 104,35 & 41,50 \\
\hline Sethoxydim & 153,37 & 80,01 & 70,50 & 169,49 & 94,55 & 166,00 & 134,08 & 83,72 & 55,70 \\
\hline Test. sem capina & 100,00 & 100,00 & 100,00 & 100,00 & 100,00 & 100,00 & 100,00 & 100,00 & 100,00 \\
\hline $\bar{F}$ & $\mathrm{NS}^{(1)}$ & NS & NS & NS & NS & NS & $\mathrm{NS}$ & NS & NS \\
\hline $\mathrm{CV}(\%)$ & 31,85 & 42,41 & 39,61 & 38,16 & 28,32 & 30,23 & 30,52 & 35,27 & 27,87 \\
\hline
\end{tabular}

Médias na mesma coluna seguidas pela mesma letra não diferem entre si pelo teste de Tukey.*(p $\leq 0,05)$. NS = não significativo. 
$\mathrm{Na}$ Tabela 5 estão apresentados os resultados das avaliações do número de dias para o início do florescimento, da altura de plantas e do diâmetro do caule na ocasião do florescimento, que ocorreu aos 80 dias após a semeadura (DAS).

Tabela 5. Início do florescimento, altura de plantas e diâmetro do caule do girassol na floração (80 DAS). Média de 4 repetições ${ }^{(1)}$. EPAMIG Centro Oeste, 2011.

\begin{tabular}{|c|c|c|c|}
\hline Tratamentos & $\begin{array}{c}\text { Início do } \\
\text { florescimento } \\
(\text { dias })\end{array}$ & $\begin{array}{l}\text { Altura de plantas } \\
(\mathbf{c m})\end{array}$ & $\begin{array}{l}\begin{array}{l}\text { Diâmetro do caule } \\
(\mathbf{c}\end{array} \\
(\mathrm{cm})\end{array}$ \\
\hline Alachlor & 74,75 & $156,9 \mathrm{AB}$ & $25,8 \mathrm{~A}$ \\
\hline Trifluralin & 70,75 & $164,6 \mathrm{AB}$ & $22,5 \mathrm{AB}$ \\
\hline Fenoxapro-p-ethyl & 76,25 & $157,8 \mathrm{AB}$ & $24,4 \mathrm{~A}$ \\
\hline Sethoxydim & 70,50 & $160,9 \mathrm{AB}$ & $23,0 \mathrm{AB}$ \\
\hline Testemunha capinada & 74,00 & $166,1 \mathrm{~A}$ & $26,0 \mathrm{~A}$ \\
\hline Testemunha sem capina & 72,25 & $147,8 \mathrm{~B}$ & $20,7 \mathrm{~B}$ \\
\hline $\bar{F}$ & $\overline{\mathrm{NS}}$ & $3,26 * *$ & $6,10^{*}$ \\
\hline $\mathrm{CV}(\%)$ & 5,03 & 4,06 & 6,62 \\
\hline
\end{tabular}

Médias na mesma coluna seguidas pela mesma letra não diferem entre si pelo teste de Tukey.*(p $\leq 0,05)$. NS = não significativo. ${ }^{(2)}$ Média de 10 plantas/parcela.

Observou-se que o início do florescimento ocorreu no intervalo de 70 a 74 dias após a semeadura (Tabela 5). Com relação à altura de plantas e ao diâmetro do caule houve diferença significativa entre os tratamentos testemunha capinada e testemunha sem capina, sendo que os maiores diâmetros foram apresentados quando da utilização dos herbicidas alachlor e fenoxaprop-p-eyhyl que não diferiram da testemunha capinada (Tabela 5). Os valores encontrados nesse ensaio para a altura e diâmetro do caule do girassol são semelhantes aos obtidos no trabalho conduzido por Erasmo et al. (2010).

A maturação fisiológica dos aquênios ocorreu aos 95 dias após a semeadura em todos os tratamentos, dados esse que concordam com os apresentados por Leite et al. (2010). O ciclo da cultura foi de 126 dias. Quanto ao diâmetro dos capítulos e ao estande final, não houve diferença significativa entre os tratamentos (Tabela 6).

Tabela 6. Diâmetro dos capítulos $(\mathrm{cm})$ e estande final do girassol, nos diferentes tratamentos. Média de 4 repetições. EPAMIG Centro Oeste, 2011.

\begin{tabular}{lcc}
\multicolumn{1}{c}{ Tratamentos } & $\begin{array}{c}\text { Diâmetro dos capítulos } \\
(\mathrm{cm})\end{array}$ & Estande final \\
\hline Alachlor & 58,50 & 31,50 \\
Trifluralin & 57,51 & 31,50 \\
Fenoxapro-p-ethyl & 55,41 & 35,00 \\
Sethoxydim & 59,46 & 29,00 \\
Testemunha capinada & 70,53 & 27,50 \\
Testemunha sem capina & 61,50 & 32,50 \\
\hline F & $1,84 \mathrm{NS}$ & $2,18 \mathrm{NS}$ \\
$\mathrm{CV}(\%)$ & 12,95 & 12,80 \\
\hline
\end{tabular}

Médias na mesma coluna seguidas pela mesma letra não diferem entre si pelo teste de Tukey.*(p $\leq 0,05)$. NS = não significativo; ${ }^{(1)}$ Média de 10 plantas/parcela.

O diâmetro dos capítulos variou entre 55,0 a $70,0 \mathrm{~cm}$. Erasmo et al (2010), trabalhando com a variedade Embrapa V122 encontraram valores para o diâmetro dos capítulos variando de 47,2 a $67,5 \mathrm{~cm}$, respectivamente, nas testemunhas sem capina e capinada. Esses autores verificaram que a testemunha sem capina da variedade Embrapa 
V122 apresentou reduções na altura de plantas, diâmetro do caule, diâmetro do capítulo e produção de grãos em relação aos resultados da testemunha capinada (Erasmo et al., 2010).

Para o número de plantas quebradas e acamadas, assim como o rendimento de aquênios não houve diferença significativa entre os tratamentos (Tabela 7). Segundo Brighenti et al. (2004) a convivência com as plantas daninhas até 21 dias após a emergência (DAE) do girassol não causou efeito sobre o rendimento da cultura e no presente trabalho houve apenas a presença de $C$. rotundus nesse período (Anexo 1). Segundo esses autores, o período total de prevenção à interferência (PTPI) foi de $30 \mathrm{DAE}$, sendo o período crítico de prevenção da interferência de 21 aos 30 dias após a emergência do girassol. No presente ensaio a infestação de $R$. sativus e $B$. decumbens teve início aos 40 dia após o plantio da cultura o que pode explicar o fato de não haver queda no rendimento da cultura na testemunha sem capina.

Tabela 7. Número de plantas quebradas, número de plantas acamadas e rendimento de aquênios do girassol, nos diferentes tratamentos. Média de 4 repetições. EPAMIG Centro Oeste, 2011.

\begin{tabular}{|c|c|c|c|c|}
\hline \multirow[b]{2}{*}{ Tratamentos } & \multirow{2}{*}{$\begin{array}{l}\text { Número de } \\
\text { plantas } \\
\text { quebradas }\end{array}$} & \multirow{2}{*}{$\begin{array}{l}\text { Número de } \\
\text { plantas } \\
\text { acamadas }\end{array}$} & \multicolumn{2}{|c|}{ Rendimento de aquênios } \\
\hline & & & (g/parcela) & (kg/ha) \\
\hline Alachlor & 0,25 & 0,75 & $1.965,00$ & $2.183,33$ \\
\hline Trifluralin & 0,50 & 0,50 & $2.100,00$ & $2.333,33$ \\
\hline Fenoxapro-p-ethyl & 0 & 0,50 & $1.935,00$ & $2.150,00$ \\
\hline Sethoxydim & 0,25 & 0 & $1.845,00$ & $2.050,00$ \\
\hline Testemunha capinada & 0 & 0 & $2.265,00$ & $2.516,67$ \\
\hline Testemunha sem capina & 0 & 0,25 & $2.025,00$ & $2.250,00$ \\
\hline $\mathrm{F}$ & - & - & $0,54 \mathrm{NS}$ & $0,54 \mathrm{NS}$ \\
\hline $\mathrm{CV}(\%)$ & & & 19,72 & 19,72 \\
\hline
\end{tabular}

Médias na mesma coluna seguidas pela mesma letra não diferem entre si pelo teste de Tukey.*(p $\leq 0,05)$. NS = não significativo.

\section{Conclusões}

Com base nos resultados do presente trabalho pode-se concluir que os herbicidas que apresentaram maior fitotoxicidade às plantas do girassol foram: imazaquin, metribuzin, chlorimuron-ethyl, [fluazifop-p + fomesafen], imazapyr e imazethapyr, causando morte das plantas ou redução drástica de sua biomassa seca.

Os herbicidas pré-emergentes alachlor e trifluralin, e os pós-emergentes fenoxaprop-pethyl e sethoxydim mostraram-se seletivos à cultura.

As espécies com as maiores densidades populacionais foram C. rotundus, $B$. decumbens e $R$. sativus.

Diferenças nos valores de frequência e densidade relativa de $B$. decumbens foram observadas quando da utilização de sethoxydim.

Alachlor e trifluralin promoveram mudanças nos padrões de frequência de $R$. sativus, ocasionando a mortalidade das plantas.

\section{Agradecimentos}

À Fundação de Amparo à Pesquisa do Estado de Minas Gerais (FAPEMIG) pelo financiamento da pesquisa e concessão da bolsa BIPDT.

\section{Referências}

BALDUÍNO, A.P.C. et al. Fitossociologia e análise comparativa da composição florística do cerrado da flora de Paraopeba - MG. Revista Árvore, v.29, n.1, p.25-34, 2005. 
BIANCHI, M.A. et al. Interferência de Raphanus sativus na produtividade de cultivares de soja. Planta Daninha, v.29, n.4, p.783-792, 2011.

BRIGHENTI, A.M. et al. Controle químico de plantas daninhas na cultura do girassol em solo de textura argilosa. Revista Brasileira de Herbicidas, v.1, n.1, p.85-88, 2000a.

BRIGHENTI, A.M. et al. Seletividade de herbicidas aplicados em condições de préemergência na cultura do girassol. Revista Brasileira de Herbicidas, v.1, n.3, p.243-247, 2000b.

BRIGHENTI, A.M. et al. Seletividade de herbicidas aplicados em pré-emergência na cultura do girassol em solo de textura argilosa. Revista Brasileira de Herbicidas, v.1, n.2, p.129-132, 2000c.

BRIGHENTI, A.M. et al. Persistência e fitotoxicidade de herbicidas aplicados na soja sobre o girassol em sucessão. Pesquisa Agropecuária Brasileira, v.37, n.4, p.559565, 2002a.

BRIGHENTI, A.M. et al. Persistência e fitotoxicidade do herbicida atrazine aplicado na cultura do milho sobres a cultura do girassol em sucessão. Planta Daninha, v.20, n.2, p.291-297, 2002b.

BRIGHENTI, A.M. et al. Cadastramento fitossociológico de plantas daninhas na cultura do girassol. Pesquisa Agropecuária Brasileira, v.38, n.5, p.651-657, 2003.

BRIGHENTI, A.M.; CASTRO, C.; OLIVEIRA JR., R.S. Períodos de interferência de plantas daninhas na cultura do girassol. Planta Daninha, v.22, n.2, p.251-257, 2004.

BRIGHENTI, A.M. et al. Atividade residual do herbicida imazaquin em cultivos sucessivos de girassol. In: KARAM, D.; MASCARENHAS, M.H.T.; SILVA, J. B. (Org.). A ciência das plantas daninhas na sustentabilidade dos sistemas agrícolas. Sete Lagoas: SBCPD: Embrapa Milho e Sorgo, 2008. 1 CD-ROM.
CASTRO, C. et al. A cultura do girassol. Londrina: Embrapa - CNPSo, 1997. 38p. (Embrapa-CNPSo. Circular Técnica, 13).

CASTRO, C.; FARIAS, J.R.B. Ecofisiologia do girassol. In: LEITE, R.M.V.B.C.; BRIGHENTI, A.M.; CASTRO, C. Girassol no Brasil. Londrina: Embrapa/CNPSo, 2005. p.163-218.

COMISSÃO DE FERTILIDADE DO SOLO DO ESTADO DE MINAS GERAIS CFSEMG. Recomendações para o uso de corretivos e fertilizantes em Minas Gerais $\mathbf{5}^{\mathbf{a}}$ Aproximação. Viçosa: CFSEMG, 1999. $359 \mathrm{p}$.

CONCENÇO, G. et al. Sulfentrazone e qualidade fisiológica das sementes de girassol. Revista Brasileira de Agrociência, v.13, n.1, p.109-113, 2007.

ERASMO, E.L. et al. Efeito de herbicidas aplicados em solo de várzea sobre a cultura do girassol. Planta Daninha, v.28, n.4, p.843852, 2010.

FLECK, N.G.; VIDAL, R.A. Injúria potencial de herbicidas de solo ao girassol. III Imazaquin e imazethapyr. Planta Daninha, v.12, n.1, p.39-43, 1994.

KARAM, D.; CRUZ, M.B. da. Sem concorrentes - manter o terreno no limpo, sem invasoras é o primeiro passo para garantir o desenvolvimento. Cultivar: Grandes Culturas, v.6, n.63, 2004. Agrotécnica. Caderno Técnico Cultivar, Pelotas, n.63, p.310, 2004. Encarte.

LEITE, R.A.; PAULA JÚNIOR, T.J.; VENZON, M. Girassol (Helianthus annuus L.). In: PAULA JÚNIOR, T.J. \& VENZON, M. (Ed.). 101 culturas: manual de tecnologias agrícolas. Belo Horizonte: Epamig, 2007. cap.53. p.397-404.

MASCARENHAS, M.H.T. et al. Seletividade de herbicidas na cultura do girassol. In: CONGRESSO BRASILEIRO DA CIÊNCIA DAS PLANTAS DANINHAS, 27, Ribeirão 
Preto, SP, 2010. Resumos expandidos..., Sociedade Brasileira da Ciência das Plantas Daninhas, 2010. CD_ROM. p.2225-2229, 2010.

MINISTÉRIO DA AGRICULTURA, PECUÁRIA E ABASTECIMENTO - MAPA. Disponível em extranet.agricultura.gov.br/agrofit_cons/princip al_agrofit_cons. Acesso em: 15 dez. 2011.

PAES, J.M.V. Utilização do girassol em sistemas de cultivo. Informe Agropecuário, v.26, n.229, p.34-41, 2005.

PITELLI, R.A.; PITELLI, R.L.C.M. Biologia e ecofisiologia das plantas daninhas. In: VARGAS, L.; ROMAN, E.S. Manual de manejo e controle de plantas daninhas. Bento Gonçalves: CNPUV, p.29-55, 2004.

RIBEIRO JR., J.I. Análises estatísticas no SAEG. Viçosa: Universidade Federal de viçosa, 2001. 301p.

ROSSI, R.O. Girassol. Curitiba: Tecnoagro, 1998. 333p.

SOCIEDADE BRASILEIRA DA CIÊNCIA DAS PLANTAS DANINHAS - SBCPD. Procedimentos para instalação, avaliação e análise de experimentos com herbicidas. Londrina: 1995. 42p.

SILVA, A.F. et al. Densidades de plantas daninhas e épocas de controle sobre os componentes de produção da soja. Planta Daninha, v.26, n.1, p.65-71, 2008.

SILVA, H.P. et al. Levantamento das plantas espontâneas na cultura do girassol. Revista Verde, v.5, n.1, p.162-167, 2010.

FLECK, N.G.; VIDAL, R.A. Injúria potencial de herbicidas de solo ao girassol. IV Rendimento de aquênios e componentes do rendimento. Planta Daninha, v.12, n.1, p.44$51,1994$. 
Anexo 1. Frequencia (Fre), densidade (Den), abundância (Abu), frequencia relativa, (Freq. R), densidade relativa (Den. R), abundância relativa (Abu. R) e índice de valor de importância (IVI) de Cyprus rotundus L na cultura do girassol aos 20, 40 e 60 dias após a aplicação dos herbicidas (DAA). EPAMIG Centro Oeste, 2010

\begin{tabular}{|c|c|c|c|c|c|c|c|c|c|c|c|c|c|c|c|c|c|c|c|c|c|}
\hline \multirow{3}{*}{ Tratamento } & \multicolumn{21}{|c|}{ Cyperus rotundus $\mathrm{L}$} \\
\hline & \multicolumn{7}{|c|}{ 20 DAA } & \multicolumn{7}{|c|}{ 40 DAA } & \multicolumn{7}{|c|}{60 DAA } \\
\hline & Freq & FreqR & Den & DenR & Abu & AbuR & IVI & Freq & FreqR & Den & DenR & Abu & AbuR & IVI & Freq & FreqR & Den & DenR & Abu & AbuR & IVI \\
\hline Alach & 1,00 & 33,33 & 22,37 & 31,62 & 22,37 & 31,62 & 96,57 & 1,00 & 33,33 & 23,75 & 39,91 & 23,75 & 39,91 & 113,15 & 1,00 & 33,33 & 24,75 & 37,94 & 24,75 & 37,94 & 109,21 \\
\hline Trifl & 1,00 &, 33 & 2 & 29,69 & 21,00 & 29 , & 92,71 & 1, & 33 & 17,75 & 29,83 & 17,75 & 29,83 & 92,99 & 1,00 & 33,33 & 22,75 & 34,86 & 22,75 & 4,86 & 103,05 \\
\hline Fenoxapro-p-ethyl & 1,00 &, 33 & 20,25 & 28,52 & 20,25 & 28,52 & 90,37 & 1,00 & 3,33 & 43,25 & 33,46 & 43,25 & 33,46 & 100,25 & 1,00 & 33,33 & 54,50 & 31,01 & 54,50 & 1,01 & 95,35 \\
\hline Sethoxydim & 1,00 & 33,33 & 27,50 & 38,73 & 27,50 & 38,73 & 110,79 & 1,00 & 33,33 & 39,75 & 30,76 & 39,75 & 30,76 & 94,85 & 1,00 & 33,33 & 57,50 & 32,72 & 57,50 & 32,72 & 98,77 \\
\hline Test. sem capina & 1,00 & 33,34 & 23,25 & 32,75 & 23,25 & 32,75 & 98,84 & 1,00 & 33,34 & 46,25 & 35,78 & 46,25 & 35,78 & 104,90 & 1,00 & 33,34 & 63,75 & 36,27 & 63,75 & 36,27 & 105,88 \\
\hline
\end{tabular}

Anexo 2. Frequencia (Fre), densidade (Den), abundância (Abu), frequencia relativa, (Freq. R), abundância relativa (Abu R) e índice de valor de importância (IVI) de Raphanus sativus L. na cultura do girassol aos 20, 40 e 60 dias após a aplicação dos herbicidas (DAA). EPAMIG Centro Oeste, 2010.

\begin{tabular}{|c|c|c|c|c|c|c|c|c|c|c|c|c|c|c|c|c|c|c|c|c|c|}
\hline \multirow{3}{*}{ Tratamento } & \multicolumn{21}{|c|}{ Raphanus sativus $L$. } \\
\hline & \multicolumn{7}{|c|}{20 DAA } & \multicolumn{7}{|c|}{ 40 DAA } & \multicolumn{7}{|c|}{ 60 DAA } \\
\hline & Freq & FreqR & Den & DenR & Abu & AbuR & IVI & Freq & FreqR & Den & DenR & Abu & AbuR & IVI & Freq & FreR & Den & DenR & Abu & AbuR & IVI \\
\hline Alachlor & 0,00 & 0,00 & 0,00 & 0,00 & 0,00 & $\overline{0,00}$ & 0,00 & 0,50 & 33,33 & 0,87 & 12,66 & 0,87 & 12,66 & 58,65 & 0,00 & 0,00 & 0,00 & 0,00 & 0,00 & 0,00 & 0,00 \\
\hline Trifluralin & 0,00 & 0,00 & 0,00 & 0,00 & 0,00 & 0 & م० & 0,50 & 3 & 5,25 & 76,42 & 5,25 & 76,42 & 186,17 & 0,00 & 0,00 & 0,00 & 0,00 & 0,00 & 0,00 & 0,00 \\
\hline Fenoxapro-p-ethyl & 0,00 & 0,00 & 0,00 & 0,00 & 0,00 & 0,00 & 0,00 & 0,50 & 25,00 & 1,25 & 15,62 & 1,25 & 15,62 & 56,24 & 0,75 & 27,28 & 6,00 & 31,58 & 6,00 & 31,58 & 90,44 \\
\hline Sethoxydim & 0,00 & 0,00 & 0,00 & 0,00 & 0,00 & 0,00 & 0,00 & 0,75 & 37,50 & 2,75 & 34,38 & 2,75 & 34,38 & 106,26 & 1,00 & 36,36 & 6,50 & 34,21 & 6,50 & 34,21 & 104,78 \\
\hline Test. sem capina & 0,00 & 0,00 & 0,00 & 0,00 & 0,00 & 0,00 & 0,00 & 0,75 & 37,50 & 4,00 & 50,00 & 4,00 & 50,00 & 137,50 & 1,00 & 36,36 & 6,50 & 34,21 & 6,50 & 34,21 & 104,78 \\
\hline
\end{tabular}

Anexo 3. Frequencia (Fre), densidade (Den), abundância (Abu), frequencia relativa, (Freq. R), abundância relativa (Abu R) e índice de valor de importância (IVI) de Brachiaria decumbens Stapf na cultura do girassol aos 20, 40 e 60 dias após a aplicação dos herbicidas (DAA). EPAMIG Centro Oeste, 2010.

\begin{tabular}{|c|c|c|c|c|c|c|c|c|c|c|c|c|c|c|c|c|c|c|c|c|c|}
\hline \multirow{3}{*}{ Tratamento } & \multicolumn{21}{|c|}{ Brachiaria decumbens Stapf } \\
\hline & \multicolumn{7}{|c|}{20 DAA } & \multicolumn{7}{|c|}{ 40 DAA } & \multicolumn{7}{|c|}{ 60 DAA } \\
\hline & Freq & FreqR & Den & DenR & Abu & AbuR & IVI & Freq & FreqR & Den & DenR & Abu & AbuR & IVI & Freq & FreqR & Den & DenR & Abu & AbuR & IVI \\
\hline Alach & 0,00 & 0,00 & 0,00 & 0,00 & 0,00 & 0,00 & 0,00 & 0,00 & 0,00 & 0,00 & 0,00 & 0,00 & 0,00 & 0,00 & 0,00 & 0,00 & 0,00 & 0,00 & 0,00 & 0,00 & 0,00 \\
\hline Trifluralin & 0,00 & 0,00 & 0,00 & 0,00 & 0,00 & 0,00 & 0,00 & 0,00 & 0,00 & 0,00 & 0,00 & 0,00 & 0,00 & 0,00 & 0,00 & 0,00 & 0,00 & 0,00 & 0,00 & 0,00 & 0,00 \\
\hline Fenoxapro-p-ethyl & 0,00 & 0,00 & 0,00 & 0,00 & 0,00 & 0,00 & 0,00 & 0,25 & 33,33 & 5,25 & 36,21 & 5,25 & 36,21 & 105,75 & 0,25 & 25,00 & 11,00 & 55,00 & 11,00 & 55,00 & 135,00 \\
\hline Sethoxydim & 0,00 & 0,00 & 0,00 & 0,00 & 0,00 & 0,00 & 0,00 & 025 & 33,33 & 4,75 & 32,76 & 4,75 & 32,76 & 98,85 & 0, & 25,00 & 2,50 & 12,50 & 2,50 & 12,50 & 50,00 \\
\hline Test. sem capina & 1,00 & 100,00 & 1,00 & 100,00 & 1,00 & 100,00 & 300,00 & 0,25 & 33,34 & 4,75 & 31,06 & 4,75 & 31,03 & 95,40 & 0,50 & 50,00 & 6,50 & 32,50 & 6,50 & 32,50 & 115,00 \\
\hline
\end{tabular}

